\title{
Special foods and local herbs used to enhance breastmilk production in Ghana: rate of use and beliefs of efficacy
}

\author{
Zakari Ali ${ }^{1,2^{*}}$ (D), Mohammed Bukari ${ }^{1}$, Anita Mwinisonaam ${ }^{1}$, Abdul-Latif Abdul-Rahaman ${ }^{1}$ and Abdul-Razak Abizari ${ }^{1}$
}

\begin{abstract}
Background: Inadequate breastmilk production is one of the key factors associated with suboptimal breastfeeding. In most local African homes, special herbs and some food items are commonly used to promote breastmilk production (known as lactogogue/galactogogue). We describe the use and characterize the herbs and food items used to promote breastmilk production in two regions of Ghana.
\end{abstract}

Methods: We conducted a cross-sectional study in 2018 involving 402 lactating mothers. The range of foods used as lactogogues was obtained from 20 participants through focus group discussions. Quantitative data on demographics, lactogogue use and feeding practices were obtained through questionnaire administration.

Results: The mean age of women was 29.2 years and children were 10 months. Breastmilk production problems were low (22.4\%) and the majority of lactating mothers felt they had adequate breastmilk (70.4\%) but awareness about lactogogues was widespread in both regions (88.8\%) and highest in the Brong-Ahafo region (90.0\%). Information about lactogogues was mainly from grandparents (24.6\%), parents (31.6), health facilities (16.5\%) and friends (12.8\%), while the media had little influence $(<1 \%)$. The majority of the mothers used lactogogues to enhance breastmilk production (67.7\%), and a quarter of them used lactogogues because of their tradition (25.2\%). Prevalence of lactogogue use was 83.8\%, lactogogues were prepared separate from household meals (59.4\%) and consumed one to three times a day (89.6\%). Users felt the effectiveness within $24 \mathrm{~h}$ of use (98.5\%). The most common lactogogues included; groundnut/peanut soup prepared with Bra leaves (Hibiscus sabdariffa), hot black tea, Werewere/Agushi (Citrulus colocynthis) prepared with Bra leaves, and Abemudro (a polyherbal formulation). Only 13.2\% of lactating mothers also used lactogogues during pregnancy.

Conclusions: Special foods and selected herbs are widely used to enhance breastmilk production in Ghana and constitute an important part of the diet of lactating mothers. These results could contribute to understanding breastfeeding behaviours and stimulate further research into evaluating the safety and scientific efficacy of these products in Ghana.

Keywords: Breastfeeding, Breastmilk, Lactogogues, Galactogogue, Lactation, Ghana

\footnotetext{
* Correspondence: zali@mrc.gm

'Department of Nutritional Sciences, School of Allied Health Sciences, University for Development Studies, P.O. Box 1883, Tamale, Ghana

${ }^{2}$ Nutrition Theme, MRC Unit The Gambia at the London School of Hygiene \& Tropical Medicine, Atlantic Boulevard, Fajara, P.O. Box 273, Banjul, The Gambia
}

(c) The Author(s). 2020 Open Access This article is licensed under a Creative Commons Attribution 4.0 International License, which permits use, sharing, adaptation, distribution and reproduction in any medium or format, as long as you give appropriate credit to the original author(s) and the source, provide a link to the Creative Commons licence, and indicate if changes were made. The images or other third party material in this article are included in the article's Creative Commons licence, unless indicated otherwise in a credit line to the material. If material is not included in the article's Creative Commons licence and your intended use is not permitted by statutory regulation or exceeds the permitted use, you will need to obtain permission directly from the copyright holder. To view a copy of this licence, visit http://creativecommons.org/licenses/by/4.0/ The Creative Commons Public Domain Dedication waiver (http://creativecommons.org/publicdomain/zero/1.0/) applies to the data made available in this article, unless otherwise stated in a credit line to the data. 


\section{Background}

Globally, an estimated $12 \%$ of mortality in children under five years of age is attributable to suboptimal breastfeeding practices [1]. Breastfeeding is considered the most important source of nutrition in the first year of life for both term and preterm infants because of its well-known positive effects on short and longterm outcomes [1]. In 2012, the World Health Assembly endorsed a comprehensive implementation plan on maternal, infant and young child nutrition, which specified six global nutrition targets to be achieved by 2025. Among others, the Resolution seeks to increase rates of exclusive breastfeeding among infants ( $<6$ months) by at least $50 \%$ [2]. Eight countries are on track to meet four targets and three of these countries are African. Ghana is on track to meet three of the targets along with 12 other countries and even though the proportion of under-five children who are exclusively breastfed in Ghana (52.1\%) is well above the west African average (32.5\%), progress has stalled in recent years [3].

Exclusive breastfeeding and appropriate complementary feeding are key to the maintenance of the nutritional wellbeing of children. In fact, promotion of optimal breastfeeding practices is one of the most effective interventions to prevent deaths in children under five years worldwide [4]. Breastfeeding is also associated with reduced risk of childhood infections and obesity, and long term benefits may include protection against the development of type-2 diabetes and other noncommunicable diseases [5]. Some studies also point to benefits in schooling years and performance $[6,7]$.

Lactation is a complex physiological mechanism involving hormonal, physical and emotional factors. Inadequate breastmilk production is among the key factors that increase the rate of suboptimal breastfeeding among lactating mothers $[8,9]$. Even though perceived insufficient breastmilk supply have been reported [10], the problem of insufficient breastmilk production persists. Different approaches to enhance breastmilk production have been explored including medication, herbal preparations and some food substances [11].

Lactogogues (or galactogogues) are substances which could be used to assist initiation, maintenance, or augmentation of the rate of maternal milk synthesis [12]. They include both pharmaceutical and herbal or foodbased preparations. The World Health Organization has mentioned its usage in stimulating increased lactation in exceptionally difficult circumstances; emphasis has only been laid on the use of pharmacological substances such as domperidone and metoclopramide with supporting evidence of effectiveness [13]. The GP Infant Feeding Network (UK), has also recommended its prescription in only exceptional circumstances [14]. The evidence base for pharmaceutical lactogogues such as domperidone and metoclopramide [15] is stronger than it is for herbal and food-based preparations where safety and concerns around insufficient study sizes have been raised [16]. While special herbs and food substances continue to be widely used in many settings around the world to enhance breastmilk production for centuries, evidence regarding their benefits or harms is largely absent.

In most local African homes, herbs and special foods are widely used in the diets of lactating mothers to enhance breastmilk production and in many cases, women without apparent milk production also use them as a customary practice. However, these practices are largely undocumented and their perceived effectiveness unknown. We aimed to describe these practices among lactating mothers in two regions of Ghana. The results could help in understanding the extent of usage and stimulate further research into the safety and scientific efficacy of common foods and herbs used as lactogogues in Ghana.

\section{Methods \\ Study area}

The study was conducted in two regions of Ghana, chosen to represent the northern and southern parts of Ghana and as much as possible reflect the diversity in cultures across the country. The then Brong-Ahafo region which has recently been further divided into three (Brong-Ahafo; Bono East; and Ahafo regions) was chosen to represent southern Ghana while the Northern region also divided into three (Northern; Savannah; and North east regions) was chosen to represent the northern part of the country.

The Brong-Ahafo region lies in the forest zone and is a major cocoa and timber producing area. The region had a population of $1,815,408$ in 2010 ; recent estimates from the regional health directorate indicates that 181 , 931 children are under five years old [17], the predominant ethnic group in the region is Akan, except in Sene where the Guans predominate. Christianity has the largest following (71.0\%), followed by Islam (16.1\%) and traditional religion (4.6\%). The literacy rate is $41.7 \%$ who can read and write English and a Ghanaian language [18, 19].

The Northern region had a census population of 2, 479,461 in 2010 . The total population of children $0-4$ years was projected to be $3,624,270$ by 2020 . The region is much drier than the southern areas of Ghana due to its proximity to the Sahel and the Sahara. The vegetation consists predominantly of grassland, especially savanna with clusters of drought-resistant trees such as baobabs or acacias. Islam is the predominant religion (56.1\%), followed by practitioners of the African traditional religion (21.3\%), while Christianity (19.3\%) and others make 
up the rest. The main ethnicities and languages spoken widely include Dagbani, Gonja and Mampruli. Literacy rate is low at $19.2 \%$ who can read and write English and a Ghanaian language $[18,20]$.

\section{Study design, population and sample}

The study used a mixed method approach involving cross-sectional administration of questionnaires and focus group discussions (FGDs). The target population for the questionnaire administration was lactating women with children aged $0-23$ months in the two regions. The focus group discussions targeted grandmothers and other elderly women who are involved in childcare and are involved in food preparation and decisions concerning lactating women as well as lactating women. We conducted one FGD in each region using a purposive sample of ten target women. Each FGD included a mix of grandmothers, lactating women and other elderly women and lasted between 45 and $60 \mathrm{~min}$. The purpose of the FGD was to identify the range of common lactogogues used in each region. Each FGD was facilitated by one research assistant and another who noted the discussions which were also recorded. The research assistants spoke the local language of the study area which made facilitation and transcription easier. Data saturation was determined when no further views were forthcoming. Information from the FGDs were also used to inform questionnaire development for the potential lactogogues mothers used. This enabled us to have good descriptions of lactogogues respondents used because we had information on the possible ways (names) specific lactogogues were referred in the two regions. Lactating mothers who participated in the FGDs were excluded from the questionnaire (quantitative) part of the study. The quantitative survey involved the administration of questionnaires to elicit the specific lactogogues used, usage frequency, perceived effectiveness and demographic characteristics of 402 women with children 0-23 months in both regions (Northern region $=202$, Brong-Ahafo region $=200$ ). The initial questionnaire was pretested on five lactating women outside the study area and feedback used to improve the questionnaire development including sequence of questions and skips. Reliability was assessed by checking content of responses for consistency. The questionnaires were interviewer-administered by graduate nutrition research assistants.

We aimed to estimate a single proportion of lactogogue use and assumed a 50\% prevalence, 5\% margin of error and a resulting required 385 sample size. To account for possible questionnaire damage or significant missing data in some questionnaires, 402 participants were targeted in the two regions instead.

\section{Sampling technique}

Purposive sampling was used to select one district from each region, districts were chosen to reflect both rural and urban mixes as possible. In the Northern region, the Nanton district was selected while the Asutifi south district was selected to represent the Brong-Ahafo region. Data collection for the questionnaire administration took place in households of a large community and each selected purposively to represent a mixture of peri-urban and rural participants from the districts. We selected the next large community if the required sample was not obtained in the initial selected community. All households with mothers who had children 0-23 months were identified in each selected community and used to construct a sampling frame for systematic random sampling. The required sample for each community was used to divide the sampling frame to give the sampling interval. A random number was chosen from the sampling interval to be the starting household; subsequent households were chosen by adding the sampling interval to the selected number. This was done until the required sample for each community was achieved, in households with more than one eligible woman, one was selected through simple random selection. All selected women agreed and consented to participate in the survey. In instances where the target women were out of the household, field staff re-visited for consent and interview. We purposively sampled FGDs participants from a different community in the selected district which was not selected for questionnaire administration.

\section{Analysis of data}

We have presented simple statistics of the quantitative data as frequencies and percentages where variables are categorical; means and standard deviations are used in continuous variables. Range of foods identified in the FGDs were used to inform the questionnaire design for each region. The data from the FGDs were further thematically analyzed to identify emerging themes/groups of lactogogues used. As our aim is to describe the usage and beliefs of efficacy, we have not run further analytical statistics.

\section{Results}

Socio-demographic characteristics of sampled lactating women in Brong-Ahafo and northern regions

The overall sample for the study was 402 lactating mothers selected from the Brong-Ahafo (200) and Northern (202) regions of Ghana. Average age of lactating mothers was $29.2 \pm 6.0$ years, those in Northern region were slightly older $(30.0 \pm 5.2$ years $)$ than in the Brong-Ahafo region ( $28.3 \pm 6.6$ years) (Data not shown). The majority of the children were less than a year old $(62.3 \%)$ and more than half were male (54.0\%). More 
than eight in ten mothers were currently married (87.6\%) and for women in the Northern region, they were all married. Nearly half $(47.0 \%)$ had completed a basic education, were traders (38.1\%) and had low/poor socioeconomic status (40.1\%) (Table 1).

\section{Dimensions of breastfeeding practice and lactogogue use in the two regions}

Maternal concerns about breastmilk production problems were low (22.4\%) and majority of them felt they had adequate breastmilk for their child (70.4\%). However, awareness about lactogogues was widespread in both regions $(88.8 \%)$ and highest in the Brong-Ahafo region $(90.0 \%)$. The lactating mothers noted a number of sources for information about lactogogues; grandparents (24.6\%) and parents (31.6) were the commonly cited sources among other sources including the health facility $(16.5 \%)$ and friends (12.8\%), but the media was not an important source of information about lactogogues $(<$

Table 1 Socio-demographic characteristics of respondents in Brong-Ahafo $(n=200)$ and Northern region $(n=202)$

\begin{tabular}{|c|c|c|c|}
\hline Characteristic & $\begin{array}{l}\text { Brong-Ahafo } \\
n(\%)\end{array}$ & $\begin{array}{l}\text { Northern } \\
n(\%)\end{array}$ & $\begin{array}{l}\text { All } \\
n(\%)\end{array}$ \\
\hline \multicolumn{4}{|l|}{ Age of children (months) } \\
\hline $0-6$ & $63(31.5)$ & $67(33.2)$ & $130(32.3)$ \\
\hline $7-12$ & $59(29.5)$ & $63(31.2)$ & $122(30.4)$ \\
\hline$>12$ & $78(39.0)$ & $72(35.4)$ & $150(37.3)$ \\
\hline \multicolumn{4}{|l|}{ Sex of child } \\
\hline Male & $113(56.5)$ & $107(53.0)$ & $220(54.7)$ \\
\hline Female & $87(43.5)$ & $95(47)$ & $182(45.3)$ \\
\hline \multicolumn{4}{|l|}{ Marital status } \\
\hline Married & $150(75.0)$ & $202(100)$ & $352(87.6)$ \\
\hline Currently unmarried & $50(25.0)$ & $0(0.0)$ & $50(12.4)$ \\
\hline \multicolumn{4}{|c|}{ Mother's educational status } \\
\hline Basic & $141(70.5)$ & $48(23.8)$ & $189(47.0)$ \\
\hline Secondary/Tertiary & $36(18.0)$ & $9(4.4)$ & $45(11.2)$ \\
\hline No formal education & $23(11.5)$ & $145(71.8)$ & $168(41.8)$ \\
\hline \multicolumn{4}{|l|}{ Occupation of mother } \\
\hline Trader/vendor & $82(41.0)$ & $71(35.2)$ & $153(38.1)$ \\
\hline Agricultural work & $40(20.0)$ & $91(45.0)$ & $131(32.6)$ \\
\hline Civil servant & $5(2.5)$ & $3(1.5)$ & $8(2.0)$ \\
\hline Others & $35(17.5)$ & $19(9.4)$ & $54(13.4)$ \\
\hline Currently not working & $38(19.0)$ & $18(8.9)$ & $56(13.9)$ \\
\hline \multicolumn{4}{|c|}{ Socio economic status (SES) } \\
\hline Poorest & $48(24.0)$ & 38 (18.8) & $86(21.4)$ \\
\hline Poor & 39 (19.0) & 36 (17.) & 75 (18.7) \\
\hline Medium & $57(38.0)$ & $24(11.8)$ & 81 (20.1) \\
\hline Wealthy & $38(19.0)$ & $42(20.8)$ & 80 (19.9) \\
\hline Wealthiest & $18(9.0)$ & $62(30.7)$ & 80 (19.9) \\
\hline
\end{tabular}

$1 \%)$. Overall use of lactogogues was $83.8 \%$ and was about five percentage points higher in the Northern region than in the Brong-Ahafo region. Apart from using lactogogues to enhance breastmilk production (67.7\%), tradition (25.2\%), first birth (3\%) and small breast size (2\%) were common reasons for lactogogues use among lactating mothers. Lactogogues were usually prepared separate from household meals (59.4\%), consumed one to three times in a day (89.6\%) and their effectiveness felt within $24 \mathrm{~h}$ of use (98.5\%). Lactogogue use in pregnancy was low (11.4\%) and only $13.2 \%$ were aware of using them during pregnancy and for this group who used them, lactogogues were used mainly after the first three months of pregnancy (73.9\%) (Table 2). The data also show that mothers who reported breastmilk production problems were more likely to use lactogogues compared to those who did not $(90.0 \%$ vrs $82.1 \%$ respectively) (data not shown).

\section{Common lactogogues used among lactating mothers}

The focused group discussions identified the common foods and herbs used by lactating mothers to aid breastmilk production. These foods and herbs were categorized into three groups: herb related lactogogues including selected local vegetables, hot lactogogues (emphasis is on eaten hot) and groundnut related lactogogues. The herb/vegetable related lactogogues comprised of: Abemudro (a polyherbal formulation), Ayoyo/Jute leaves (Corchorus olitorius), Nkontonmire/cocoyam leaves (Colocasia esculenta), Kuuka/ dried baobab leaves (Adansonia digitata) and tiger nuts (Cyperus esculentus). Hot lactogogues included; hot millet porridge, hot black tea, hot salt petre porridge and hot Tuo Zaafi (made from maize flour). Groundnut/peanut related lactogogues consisted of mashed kenkey with groundnut, corn porridge with groundnut, Aleefu (Amaranth sp.) prepared with groundnut, Bra leaves (Hibiscus sabdariffa) soup with groundnut, Werewere (Citrulus colocynthis) soup; and groundnut only soup (Data not shown).

While some lactogogues were used widely in both regions, others were used mainly in one region and only sparingly in the other. For example, hot lactogogue use was higher in the Northern region $(96.0 \%)$ than in the Brong-Ahafo region (5.6\%). However, groundnut related lactogogues were 35 percentage points higher in the Brong-Ahafo region than in the Northern region. The herbs were also commonly used in the Brong-Ahafo region (43.5\%) than in the Northern region (18.5\%) (Table 3).

\section{Discussion}

This study sought to describe the food items and herbs used to enhance breastmilk production and the beliefs of 
Table 2 Factors related to the use of lactogogues to enhance breastmilk production

\begin{tabular}{|c|c|c|c|c|c|}
\hline Variable & $N^{\mathrm{a}}$ & $\begin{array}{l}\text { Brong-Ahafo } \\
\text { region } \\
n(\%)\end{array}$ & $N^{\mathrm{a}}$ & $\begin{array}{l}\text { Northern } \\
\text { region } \\
n(\%)\end{array}$ & $\begin{array}{l}\text { All } \\
n(\%)\end{array}$ \\
\hline Do you have breastmilk production problem? & 200 & & 202 & & \\
\hline Yes & & $48(24.0)$ & & $42(20.8)$ & $90(22.4)$ \\
\hline Do you feel your breastmilk is adequate for your child? & 127 & & 130 & & 257 \\
\hline No & & $64(50.4)$ & & $12(9.2)$ & $76(29.6)$ \\
\hline Awareness on special foods/herbs used to enhance breastmilk production & 200 & & 202 & & \\
\hline Yes & & $180(90.0)$ & & $177(87.6)$ & $\begin{array}{l}357 \\
(88.8)\end{array}$ \\
\hline $\begin{array}{l}\text { Where did you learn about the use of special foods/herbs for breastmilk } \\
\text { production? }\end{array}$ & 180 & & 178 & & \\
\hline Grandparents & & $40(22.2)$ & & $48(27.0)$ & $88(24.6)$ \\
\hline Health facility & & $28(15.6)$ & & $31(17.4)$ & $59(16.5)$ \\
\hline Parents & & $81(45.0)$ & & $32(18.0)$ & $\begin{array}{l}113 \\
(31.6)\end{array}$ \\
\hline Friends & & $10(5.6)$ & & $36(20.2)$ & $46(12.8)$ \\
\hline Media & & $0(0.0)$ & & $1(0.6)$ & $1(0.3)$ \\
\hline Others & & $21(11.7)$ & & $30(16.9)$ & $51(14.2)$ \\
\hline Do you use lactogogues? & 200 & & 202 & & \\
\hline Yes & & $163(81.5)$ & & $174(86.1)$ & $\begin{array}{l}337 \\
(83.8)\end{array}$ \\
\hline What is your main reason for using lactogogues? & 163 & & 174 & & \\
\hline Enhance breastmilk production & & $74(45.4)$ & & $154(88.5)$ & $\begin{array}{l}228 \\
(67.7)\end{array}$ \\
\hline Tradition & & $80(49.1)$ & & $5(2.9)$ & $85(25.2)$ \\
\hline This is my first birth & & $2(1.2)$ & & $7(4.0)$ & $9(2.7)$ \\
\hline Breast size small & & $4(2.5)$ & & $1(0.6)$ & $5(1.5)$ \\
\hline Others & & $3(1.8)$ & & $7(4.0)$ & $10(2.9)$ \\
\hline Number of times special foods/herbs taken in a day & 163 & & 174 & & \\
\hline $1-3$ times & & $156(95.7)$ & & $146(83.9)$ & $\begin{array}{l}302 \\
(89.6)\end{array}$ \\
\hline Above 3 times & & $7(4.3)$ & & $28(16.1)$ & $35(10.4)$ \\
\hline How was special food/herb used? & 163 & & 174 & & \\
\hline Added to usual food & & $88(54.0)$ & & $28(16.1)$ & $\begin{array}{l}116 \\
(34.4)\end{array}$ \\
\hline Prepared separately & & $54(33.1)$ & & $146(83.9)$ & $200(59.4$ \\
\hline Others & & $21(12.9)$ & & $0(0.0)$ & $21(6.2)$ \\
\hline Time taken to experience the effect of the special food/ herb after utilization & 163 & & 174 & & \\
\hline Within $24 \mathrm{~h}$ & & $158(96.9)$ & & $174(100.0)$ & $\begin{array}{l}332 \\
(98.5)\end{array}$ \\
\hline Within a week & & $5(3.1)$ & & $0(0.0)$ & $5(1.5)$ \\
\hline Awareness of lactogogue use during pregnancy & 200 & & 202 & & \\
\hline Yes & & $32(16.0)$ & & $21(18.4)$ & $53(13.2)$ \\
\hline Use of lactogogues during pregnancy & 200 & & 202 & & \\
\hline Yes & & $26(13.0)$ & & $20(9.9)$ & $46(11.4)$ \\
\hline
\end{tabular}


Table 2 Factors related to the use of lactogogues to enhance breastmilk production (Continued)

\begin{tabular}{|c|c|c|c|c|c|}
\hline Variable & $N^{a}$ & $\begin{array}{l}\text { Brong-Ahafo } \\
\text { region } \\
n(\%)\end{array}$ & $N^{\mathrm{a}}$ & $\begin{array}{l}\text { Northern } \\
\text { region } \\
n(\%)\end{array}$ & $\begin{array}{l}\text { All } \\
n(\%)\end{array}$ \\
\hline Stage of pregnancy in which special food/herb was used & 26 & & 20 & & \\
\hline $0-3$ months & & $5(19.2)$ & & $7(35.0)$ & $12(26.1)$ \\
\hline $4-6$ months & & $12(46.2)$ & & $10(50.0)$ & $22(47.8)$ \\
\hline 7-9 months & & $9(34.6)$ & & $3(15.0)$ & $12(26.1)$ \\
\hline
\end{tabular}

${ }^{\mathrm{a}} \mathrm{N}$ changes depending on relevant skips in the questions

their effectiveness in two regions of Ghana. The results show that special foods and selected herbs are widely used to enhance breastmilk production in Ghana and constitute an important part of the diet of lactating mothers. These special herbs and selected foods have been categorized into three groups; groundnut related lactogogues, herb related lactogogues and hot related/ consumed lactogogues. There were few reported problems with breastmilk production and use of lactogogues in pregnancy.

Awareness of the use of selected foods and herbs to aid in breastmilk production was high in both regions, this is consistent with studies conducted in Malaysia and Australia [16, 21] where high knowledge on breastmilk production aids were reported. A study in the United States also reported high awareness on the use of special aids especially fenugreek to promote breastmilk production [11]. People with knowledge would have been aware of substances used to help in breastmilk production, in most cases awareness increases curiosity and the urge to learn more about these substances and hence the high level of knowledge reported.

The current study showed that most lactating women obtained information on selected foods and special herbs from the home mostly parents and grandparents. Contrary to the findings of the current study, some studies have reported the internet as a major source [11], for other studies, friends and family [21] and health service providers $[22,23]$ were the main sources of information on breastmilk production aids. Our results are consistent with the study by Budzynska et al. [24] in which most cultures transfer knowledge of breastmilk productions aids from generation to generation.

The high prevalence of lactogogue use among lactating women in both regions is consistent with earlier studies [25-27] but a little higher than reported in studies from some developed countries [11, 23, 28]. Wealth inequality could play a role in healthcare access and delivery, respondents in the current study (a developing country setting) where healthcare access is relatively low may be less likely to seek professional advice from healthcare professionals, thus resorting to information from the family on which foods and special herbs could be used to support breastmilk production. It is expected that access to professional advice might have increased the options available for respondents from developed countries and, therefore, the low usage of breastmilk production aids especially herbs that may have little scientific evidence of efficacy and less likely to be recommended by professionals. A few mothers reported having breastmilk production problems but the majority still used lactogogues, this finding may suggest that these foods and herbs are used largely for prophylactic purposes or as part of usual postpartum diet rather than as a lactogogue or for curative purposes. However, we are unable to determine how many mothers are reporting

Table 3 Common lactogogues used among lactating mothers

\begin{tabular}{|c|c|c|c|c|c|}
\hline Class of lactogogues & $N^{\mathrm{a}}$ & $\begin{array}{l}\text { Brong-Ahafo region } \\
n(\%)\end{array}$ & $N^{\mathrm{a}}$ & $\begin{array}{l}\text { Northern region } \\
n(\%)\end{array}$ & $\begin{array}{l}\text { All } \\
n(\%)\end{array}$ \\
\hline Groundnut related lactogogue & 161 & & 173 & & \\
\hline Yes & & $129(80.1)$ & & $78(45.1)$ & $207(62.0)$ \\
\hline Herb related lactogogue & 161 & & 173 & & \\
\hline Yes & & $70(43.5)$ & & $32(18.5)$ & $102(30.5)$ \\
\hline Hot related lactogogue $^{b}$ & 161 & & 173 & & \\
\hline Yes & & $9(5.6)$ & & $166(96.0)$ & $175(52.4)$ \\
\hline Others & 161 & $88(54.7)$ & 173 & $17(9.8)$ & 105 (31.4) \\
\hline
\end{tabular}

$N^{a}$ changes depending on relevant skips in the questions. ${ }^{b}$ Hot related lactogogue: prepared and eaten hot 
no breastmilk problems because they had used lactogogues as a prophylaxis.

The current study showed that almost all respondents from both regions reported experiencing the effect of lactogogues within $24 \mathrm{~h}$ of use. Similarly, other studies reported effectiveness of lactogogues within 24-72 h [12, 29]. However, some studies have reported increased breastmilk production following lactogogue intake without indication of the duration for which effectiveness was felt $[21,30]$. This highlights that breastmilk production aids such as the selected foods and special foods are highly perceived to be effective, irrespective of the time taken for their effects to be felt but this finding does not indicate scientifically proven efficacy because they are participant perception of effectiveness.

The high use of groundnut/peanut in most of the lactogogues preparations, especially in the BrongAhafo region have been reported in other settings. The most popular lactogogue, fenugreek, used mostly in Europe and Asian countries [12, 31, 32] is from the pea family which includes groundnuts. Differences in which sub-type of the pea family is used may be geographically dependent on availability. Groundnuts are abundant in Ghana as opposed to fenugreek. There have been reports in the literature about their use and potential to increase breastmilk production [33]. They are protein rich foods which are believed to explain the lactogenic effect. The exact mechanisms are yet unknown but proposed to be through the action of special amino acids which are absorbed into the blood stream and synthesized to milk proteins, such as whey and casein in the mammary glands [34]. They could also exert a lactogenic effect by providing a source of fatty acids for breastmilk production [28].

Lactogogues taken hot (hot-related) were also widely used in the enhancement of breastmilk production mostly in the Northern region of Ghana especially hot black tea. This finding is in line with a study which identified black tea (Camellia sinensis) as a lactogogue even though caution was indicated due to the presence of caffeine in most commonly used brands in our setting which could cause irritability in the child if taken in excess [34]. The women particularly emphasized that the tea needed to be hot to be effective. Taking into consideration the temperature of the tea and the components of the tea, there are two schools of thought on the mechanism of action to promote breastmilk production in lactating women. The first being that tea contains polyphenols and flavonoids which are important components that promote breastmilk production through an interaction with dopamine receptors [35], and the second explanation being that, the hot temperature of the tea might cause a rapid increase in blood circulation or stimulate circulation for faster let down of milk. Mothers also said the hot tea 'melts' the contents of the breast for more milk production.

Herb and selected local vegetables were also a major lactogogue in this Ghanaian population. Their use was, however, relatively low compared to the other lactogogue types. The common herb used in the Brong-Ahafo region was Abemudro (a polyherbal formulation) mostly used to improve lactation, an earlier study in the eastern region of Ghana also reported its usage [26]. The use of lactogogues during pregnancy, though low, it was believed to prepare the breast for more milk production after birth.

Our results could be useful in targeted education for lactating women. Knowledge about the food items, herbs and beliefs of efficacy could also help healthcare professionals plan contents of educational programmes targeted at lactating mothers. This is important given the high belief of efficacy in these products without established scientific evidence of any effect. We can only reasonably speculate that because the herbs and foods identified in this study are commonly used in Ghana without apparent health harms may indicate some level of safety. However, as we show in this study, usage frequency and modes of preparation of these products may be different when they are destined for lactogogues than for normal usage. Therefore, there is the need for further research to determine their level of safety and efficacy as lactogogues in Ghana. In addition, high beliefs in the efficacy of local herbs and selected food items in promoting breastmilk production could mean that lactating women who have breastmilk production problems may not or will delay in seeking professional care, thus affecting effective breastfeeding. Therefore, it is important for healthcare professionals engaged in breastfeeding promotion to be aware of these practices and beliefs in order to identify and encourage those with problems to seek professional help.

This study has a number of strengths such as the use of FGDs to enhance a comprehensive profile of lactotogues used in the study areas. The use of two regions, chosen to represent the northern and southern parts of Ghana has enabled documentation of the different lactogogue use and practices. However, the study has some limitations worth noting. The exclusion of nonbreastfeeding women likely introduced some bias in the lactogogue practices as experiences of current lactating women and non-lactating women may be different. However, inclusion of current lactating women possibly improved recall of lactogogue practices and beliefs. It is also possible that women who are more interested in using some foods and herbs as lactogogues during breastfeeding may recall their practices differently. In 
spite of these limitations, this study has provided ample light on the practices and beliefs of efficacy of special foods and local herbs used in promoting lactation in Ghana.

\section{Conclusions}

Special foods and selected herbs are widely used to enhance breastmilk production in Ghana and constitute an important part of the diet of lactating mothers. These results could contribute to understanding breastfeeding behaviours and stimulate further research into evaluating the safety and scientific efficacy of these products in Ghana.

\section{Acknowledgements}

The authors acknowledge the support of the districts of the study and the women for their participation. We also thank Ms. Joana Nyarko Prempeh for her assistance on the project.

\section{Authors' contributions}

ZA, AM, ALAR and ARA conceptualized and designed the study. AM and ALAR collected data. ZA, MB, AM and ALAR analyzed and interpreted the data. $Z A, M B$ and $A M$ drafted the initial manuscript. ZA and ARA reviewed it critically for intellectual content. ZA, MB and ARA have primary responsibility for the final content. All authors read and approved the final manuscript for submission.

\section{Funding}

We did not receive funding for this study.

\section{Availability of data and materials}

The data supporting the conclusions of this article are included within the manuscript. The dataset could be obtained from the corresponding author upon reasonable request.

\section{Ethics approval and consent to participate}

Permissions to conduct the study in the selected districts were acquired from the Joint Ethical Review Committee of the School of Medicine and Health Sciences and School of Allied HealthSciences, University for Development Studies (UDSIRB/CMN/1569/17) and the various health directorates of the two regions. Informed consent was sought at the household level before the questioning began. The participants were guaranteed privacy and confidentiality during data collection. Finally, there was assurance of withdrawal of the participant at any time.

\section{Consent for publication}

Not applicable.

\section{Competing interests}

The authors declare that they have no competing interests.

Received: 22 July 2020 Accepted: 3 November 2020

Published online: 16 November 2020

\section{References}

1. Black RE, Victora CG, Walker SP, Bhutta ZA, Christian P, De Onis M, et al. Maternal and child undernutrition and overweight in low-income and middle-income countries. Lancet. 2013;382(9890):427-51.

2. World Health Organization (WHO): Global nutrition targets 2025. 2014.WHO: Available at: https://www.who.int/nutrition/global-target-2025/en/.

3. Development Initiatives: 2020 Global nutrition report: Action on equity to end malnutrition 2020. Available at: https://globalnutritionreport.org/ reports/2020-global-nutrition-report/.

4. Bhutta ZA, Das JK, Rizvi A, Gaffey MF, Walker N, Horton S, et al. Evidencebased interventions for improvement of maternal and child nutrition: what can be done and at what cost? Lancet. 2013;382(9890):452-77.
5. Bernardo H, Cesar V, World Health Organization: long-term effects of breastfeeding: a systematic review. 2013. no. 9241505303 Available at: https://apps.who.int/iris/bitstream/handle/10665/79198/9789241505307_ eng.pdf.

6. Anderson JW, Johnstone BM, Remley DT. Breast-feeding and cognitive development: a meta-analysis. Am J Clin Nutr. 1999;70(4):525-35.

7. Victora CG, Horta BL, de Mola CL, Quevedo L, Pinheiro RT, Gigante DP, et al. Association between breastfeeding and intelligence, educational attainment, and income at 30 years of age: a prospective birth cohort study from Brazil. Lancet Glob Health. 2015;3(4):e199-205.

8. Budzynska K, Gardner ZE, Low Dog T, Gardiner P. Complementary, holistic, and integrative medicine: advice for clinicians on herbs and breastfeeding. Pediatr Rev. 2013:34(8):343-53.

9. Mehta A, Rathi AK, Kushwaha KP, Singh A. Relactation in lactation failure and low milk supply. Sudanese J Paediatrics. 2018;18(1):39-47.

10. Sim TF, Hattingh HL, Sherriff J, Tee LB. The use, perceived effectiveness and safety of herbal galactagogues during breastfeeding: a qualitative study. Int J Environ Res Public Health. 2015;12(9):11050-71.

11. Bazzano AN, Cenac L, Brandt AJ, Barnett J, Thibeau S, Theall KP. Maternal experiences with and sources of information on galactagogues to support lactation: a cross-sectional study. Int J Women's Health. 2017;9:105-13.

12. Turkyılmaz C, Onal E, Hirfanoglu IM, Turan O, Koç E, Ergenekon E, et al. The effect of galactagogue herbal tea on breast milk production and short-term catch-up of birth weight in the first week of life. J Altern Complement Med. 2011:17(2):139-42.

13. World Health Organization. Infant and young child feeding: model chapter for textbooks for medical students and allied health professionals. WHO: World Health Organization; 2009.

14. Santhanam L: Indications for use of a galactagogue. 2019. Available at: https://gpifn.org.uk/galactagogues/.

15. Grzeskowiak LE, Wlodek ME, Geddes DT. What evidence do we have for pharmaceutical galactagogues in the treatment of lactation insufficiency? - a narrative review. Nutrients. 2019;11(5):974.

16. Brodribb W. Academy of breastfeeding medicine: ABM clinical protocol\# 9: use of galactogogues in initiating or augmenting maternal milk production, second revision 2018. Breastfeed Med. 2018;13(5):307-14.

17. Ghana Health Service: Nutritional status of children 0-59 months. 2018. Available at: www.ghanahealthservice.org

18. Ghana Statistical Service: 2010 Population and housing census summary report of final results 2012. Available at: https:/www.statsghana.gov.gh/ gssmain/storage/img/marqueeupdater/Census2010_Summary_report_of_ final_results.pdf.

19. Ghana Statistical Service: 2010 Population and housing census regional analytical report: Brong Ahafo region 2014. Available at: https://s3-us-west-2. amazonaws.com/new-ndpc-static1/CACHES/PUBLICATIONS/2019/01/21/201 0_PHC_Regional_Analytical_Reports_Brong_Ahafo_Region+.pdf.

20. Ghana Statistical Service: 2010 Population and housing census regional analytical report: Northern Region 2014. Available at: https://www2. statsghana.gov.gh/docfiles/2010phc/2010_PHC_Regional_Analytical_ Reports_Northern_Region.pdf.

21. Othman N, Lamin RAC, Othman CN. Exploring behavior on the herbal galactagogue usage among Malay lactating mothers in Malaysia. Procedia Soc Behav Sci. 2014:153:199-208.

22. Amer MR, Cipriano GC, Venci JV, Gandhi MA. Safety of popular herbal supplements in lactating women. J Hum Lact. 2015;31(3):348-53.

23. Steyn N, Zunza M, Decloedt E. A cross-sectional descriptive study of breastfeeding behaviour and galactogogue use among private-sector patients in Cape Town, South Africa. South Afr J Obstetrics Gynaecol. 2017; 23(1):20-3.

24. Budzynska K, Gardner ZE, Dugoua J-J, Low Dog T, Gardiner P. Systematic review of breastfeeding and herbs. Breastfeed Med. 2012;7(6):489-503.

25. Dahlen HG, Homer CSE. Infant feeding in the first 12 weeks following birth: a comparison of patterns seen in Asian and non-Asian women in Australia. Women Birth. 2010;23(1):22-8.

26. Dickson RA, Amponsah IK, Annan K, Fleischer TC. Nutritive potential of a polyherbal preparation fro $\mathrm{m}$ some selected Ghanaian herbs. J Plant Product Plant Resources. 2014;4(3):77-81.

27. Sreeja S, Anju V, Sreeja S. In vitro estrogenic activities of fenugreek Trigonella foenum graecum seeds. Indian J Med Res. 2010;131(6):814-9.

28. Zapantis A, Steinberg JG, Schilit L. Use of herbals as galactagogues. J Pharm Pract. 2012;25(2):222-31. 
29. Huggins K. Fenugreek: one remedy for low milk production. Rental Roundup. 1998;15(1):16-7.

30. Jensen R. Fenugreek, overlooked but not forgotten. UCLA Lactation Alumni Newsletter. 1992;1:2-3.

31. Penagos Tabares F, Bedoya Jaramillo JV, Ruiz-Cortés ZT. Pharmacological overview of galactogogues. Vet Med Int. 2014;2014:602894.

32. Srinivas R, Eagappan K, Sasikumar S. The effect of naturally formulated galactogogue mix on breast milk production, prolactin level and short-term catch-up of birth weight in the first week of life. Int J Health Sci Res. 2014; 4(10):242-53.

33. Sari DK: Effect of peanut extract consumption on the fluency of breastmilk production among lactating women in Kediri. In: 2nd International Conference on Public Health: 2017. p. 208. http://theicph.com/id_ID/201 7/11/14/effect-of-peanut-extract-consumption-on-the-fluency-of-breastmilkproduction-among-lactating-women-in-kediri/attachment/124/.

34. Panter KE, James LF. Natural plant toxicants in milk: a review. J Anim Sci. 1990;68(3):892-904.

35. Ağagündüz D. Determination of the total antioxidant and oxidant status of some galactagogue and herbal teas. Food Sci Human Wellness. 2020, (In press). https://doi.org/10.1016/j.fshw.2020.06.002.

\section{Publisher's Note}

Springer Nature remains neutral with regard to jurisdictional claims in published maps and institutional affiliations.

Ready to submit your research? Choose BMC and benefit from:

- fast, convenient online submission

- thorough peer review by experienced researchers in your field

- rapid publication on acceptance

- support for research data, including large and complex data types

- gold Open Access which fosters wider collaboration and increased citations

- maximum visibility for your research: over $100 \mathrm{M}$ website views per year

At BMC, research is always in progress.

Learn more biomedcentral.com/submissions 